\title{
Impaired T-Cell Regulation of B-Cell Growth in Helicobacter pylori-Related Gastric Low-Grade MALT Lymphoma
}

\author{
MARIO M. D’ELIOS,* AMEDEO AMEDEI,* MARTA MANGHETTI, ${ }^{\dagger}$ FRANCESCO COSTA, ${ }^{\dagger}$ \\ COSIMA T. BALDARI,§ ADNAN S. QUAZI," JOHN L. TELFORD, SERGIO ROMAGNANI,* \\ and GIANFRANCO DEL PRETE* \\ *Department of Internal Medicine and Immunoallergology, University of Florence, Florence; ₹Gastroenterology Unit, University of Pisa, Pisa; \\ §Department of Evolutionary Biology, University of Siena, Siena; and "Chiron Research Center, Siena, Italy
}

Background \& Aims: Neoplastic B cells of the Helicobacter pylori-related low-grade gastric mucosa-associated lymphoid tissue (MALT) lymphoma are responsive to $\mathrm{T}$ helper cells and sensitive to withdrawal of $H$. pylori-induced T-cell help. Methods: The clonal progeny of T cells from the gastric mucosa of 5 patients with MALT lymphoma was compared with that of T-cell clones obtained from $5 \mathrm{H}$. pylori-infected patients with chronic gastritis. Results: T-cell clones were assessed for specificity to $H$. pylori, cytokine profile, help for B-cell proliferation, and perforin- or Fas-mediated cytotoxic regulation of B-cell growth. Twenty-eight of 165 $\mathrm{CD}^{+}$gastric clones from MALT lymphoma and 33 of $178 \mathrm{CD}^{+}{ }^{+}$clones from chronic gastritis recognized $H$. pylori antigens. Cytokine production was similar in the 2 series of clones. All MALT lymphoma-derived clones dose-dependently increased their B-cell help, whereas clones from chronic gastritis lost helper activity at T-to-B-cell ratios greater than 1 because of concomitant cytolytic killing of B cells. T-cell clones from MALT lymphoma had both reduced perforin-mediated cytotoxicity and poor ability to induce Fas-mediated apoptosis. These defects were limited to gastric $T$ cells. Conclusions: $H$. pylori-induced T cell-dependent B-cell activation and deficient cytotoxic control of B-cell growth may link $H$. pylori infection, local T-cell response, and genesis of low-grade gastric MALT lymphoma.

\footnotetext{
A strong link has been documented between Helicobacter pylori infection and development of the gastric mucosa-associated lymphoid tissue (MALT) lymphoma. ${ }^{1-3}$ A prerequisite for lymphomagenesis is the development of secondary inflammatory MALT induced by chronic $H$. pylori challenge. ${ }^{3}$ The tumor cells of low-grade gastric MALT lymphoma are memory B lymphocytes still responsive to differentiation signals, such as CD40 costimulation and cytokines produced by antigenstimulated T-helper (Th) cells, ${ }^{4}$ and their growth depends
}

on stimulation by $H$. pylori-specific T cells. ${ }^{5,6}$ In early phases, this tumor is sensitive to withdrawal of $H$. pylori-induced T-cell help, providing an explanation for both the tumor's tendency to remain localized to the primary site and its regression after $H$. pylori is eradicated with antibiotics. ${ }^{7,8}$

Tumor growth may depend on evasion from $\mathrm{T}$ cellmediated cytotoxicity. ${ }^{9}$ Two cytotoxic mechanisms are known ${ }^{10}$ : the first involves local release of perforins and granzymes by effector $\mathrm{T}$ cells and leads to lysis of target cells, ${ }^{11}$ and the second induces apoptosis upon the interaction of Fas ligand expressed by $\mathrm{T}$ cells with Fas on target cells. ${ }^{12}$ Both mechanisms require antigen-induced T-cell activation, resulting in degranulation or Fas ligand up-regulation. $\mathrm{T}$ cell-mediated signaling up-regulates Fas expression and Fas-mediated apoptosis in activated B cells. ${ }^{13}$ The role of this regulatory mechanism is highlighted by the notion that both lpr and gld mice, with mutations in Fas or Fas ligand genes, develop lymphoproliferative disorders. ${ }^{14,15}$

The aims of this study were (1) to provide evidence for the presence of $H$. pylori-specific Th cells in the context of low-grade gastric MALT lymphoma, (2) to define these cells' cytokine patterns and mode of delivering help for B-cell proliferation, and (3) to assess whether gastric T cells from MALT lymphoma have normal perforin- and/or Fas-mediated regulatory mechanisms of B-cell proliferation.

\footnotetext{
Abbreviations used in this paper: APC, antigen-presenting cell; CagA, recombinant cytotoxin-associated protein; EBV, Epstein-Barr virus; EBV-B cells, Epstein-Barr virus-transformed lymphoblastoid $B$ cells; HSP, recombinant heat shock protein; IL, interleukin; MALT, mucosa-associated lymphoid tissue; PPD, purified protein derivative; PMA, phorbol-12-myristate 13-acetate; VacA, recombinant vacuolating cytotoxin.

(1) 1999 by the American Gastroenterological Association $0016-5085 / 99 / \$ 10.00$
} 


\section{Materials and Methods}

\section{Patients}

Five untreated patients ( 2 men and 3 women; mean age, 68 years; range, 62-76 years) with low-grade B-cell lymphoma of gastric MALT and 5 patients $(2$ men and 3 women; mean age, 60 years; range, 56-69 years) with uncomplicated chronic gastritis provided informed consent for this study, which was performed after approval by the local ethical committee. Multiple biopsy specimens were obtained from the gastric antrum of patients with chronic gastritis. In patients with low-grade MALT lymphoma, biopsy specimens were obtained from perilesional regions. Biopsy specimens were used for diagnosis (positive urease test, typing of $H$. pylori strain, and histology) and culture of tumor-infiltrating T lymphocytes. All patients with chronic gastritis or MALT lymphoma were infected with $\mathrm{CagA}^{+} \mathrm{VacA}^{+} H$. pylori type I strains and were positive for anti-CagA serum immunoglobulin (Ig) G antibodies, as assessed by Western blot analysis (Helicoblot 2.0; Genelabs Diagnostic, Geneva, Switzerland).

\section{Generation of $H$. pylori-Specific T-Cell Clones}

Biopsy specimens were cultured for 7 days in RPMI 1640 medium supplemented with human interleukin (IL)-2 $(50 \mathrm{U} / \mathrm{mL}$ ) (Eurocetus, Milan, Italy) to expand in vivoactivated $\mathrm{T}$ cells. ${ }^{16}$ Mucosal specimens were disrupted and single T-cell blasts were cloned under limiting dilution $(0.3$ cells/well) as reported previously. ${ }^{16,17}$ Each clone was screened (in triplicate cultures for each condition) for responsiveness to $H$. pylori antigens by measuring $\left[{ }^{3} \mathrm{H}\right]$ thymidine uptake after 60 hours' stimulation with medium, $H$. pylori lysate (aqueous extract of NCTC11637 strain, $10 \mu \mathrm{g} / \mathrm{mL}$ being optimal), purified urease, ${ }^{18}$ recombinant cytotoxin-associated protein (CagA), recombinant vacuolating cytotoxin (VacA), or recombinant heat shock protein (HSP) $(1 \mu \mathrm{g} / \mathrm{mL}$ was optimal) in the presence of irradiated autologous mononuclear cells as antigenpresenting cells (APCs), as previously reported in detail. ${ }^{16} \mathrm{~A}$ mitogenic index greater than 10 was considered a positive result. T-cell clones specific for purified protein derivative (PPD) of Mycobacterium tuberculosis were derived from peripheral blood T cells of all patients, as reported. ${ }^{17}$

\section{Cytokine Profile of $H$. pylori-Specific Gastric T-Cell Clones}

To assess the cytokine production of $H$. pylori-specific Th clones, $10^{6} \mathrm{~T}$-cell blasts of each clone were cocultured in duplicate cultures for 48 hours in $1 \mathrm{~mL}$ of medium with $5 \times$ $10^{5}$ irradiated autologous peripheral blood mononuclear cells as APCs and $H$. pylori lysate $(10 \mu \mathrm{g} / \mathrm{mL}) .{ }^{16}$ To induce cytokine production by gastric T-cell clones with unknown specificity, T-cell blasts were stimulated for 36 hours with phorbol-12myristate 13 -acetate (PMA, $10 \mathrm{ng} / \mathrm{mL}$ ) plus anti-CD3 monoclonal antibody $(200 \mathrm{ng} / \mathrm{mL})$, as detailed previously. ${ }^{17}$ Duplicate samples of each supernatant were assayed for interferon (IFN)- $\gamma$
(BioSource International, Camarillo, CA), IL-4, and IL-5 (R\&D Systems, Minneapolis, MN). IL-2, IFN- $\gamma$, IL-4, IL-5, and IL-13 (and L32 or GAPDH house-keeping genes, as controls) messenger RNA expression was determined by a multiprobe RNAse Protection Assay system (Pharmingen, San Diego, CA), according to the manufacturer's protocol. ${ }^{19}$

\section{Helper Activity of T-Cell Clones for B-Cell Proliferation}

The ability of gastric Th clones to induce B-cell proliferation was assessed by measuring $\left[{ }^{3} \mathrm{H}\right]$ thymidine uptake by peripheral blood $\mathrm{B}$ cells $\left(3 \times 10^{4}\right)$ cocultured for 4 days with different concentrations of irradiated $(2000 \mathrm{rad})$ autologous clonal T-cell blasts $(0.2,1$, and $5 \mathrm{~T}$-B-cell ratio) with or without $H$. pylori antigen, as described previously. ${ }^{16} \mathrm{~B}$ cellenriched suspensions were prepared by a double-step rosetting with neuraminidase-treated sheep red blood cells, as described. ${ }^{20}$ Peripheral blood B cell-enriched suspensions usually consisted of $68 \%-87 \%$ B cells, 9\%-21\% monocytes, and less than $1 \% \mathrm{~T}$ cells. They are referred to as $\mathrm{B}$ cells in this article.

\section{Perforin-Mediated Cytolytic Activity}

Perforin-mediated cytolytic activity of T-cell clones was assessed as reported previously. ${ }^{16}$ T-cell blasts of $H$. pylori-specific clones were incubated at 10-, 5-, and 2.5-to-1 ratios with ${ }^{51} \mathrm{Cr}$-labeled autologous Epstein-Barr virus (EBV)transformed lymphoblastoid B cells (EBV-B cells) preincubated with $H$. pylori antigen. After centrifugation to favor T-B-cell contact, microplates were incubated for 8 hours at $37^{\circ} \mathrm{C}$ and $0.1 \mathrm{~mL}$ of supernatant was removed for measurement of ${ }^{51} \mathrm{Cr}$ release. Maximum release (MR) was obtained by treating target cells with $0.1 \mathrm{~mL}$ of $1 \mathrm{~mol} / \mathrm{L} \mathrm{HCl}$. Spontaneous release (SR) was determined in microcultures without $\mathrm{T}$ cells. Specific lysis was calculated according to the following formula: \% Specific Lysis $=100($ Experimental Release $-\mathrm{SR}) /(\mathrm{MR}-\mathrm{SR})$. Cultures in which ${ }^{51} \mathrm{Cr}$ release exceeded the mean SR by more than $5 \mathrm{SD}$ were considered positive for cytolytic activity. In T-cell clones with unknown specificity, perforin-mediated cytotoxicity was tested by a lectin-dependent assay against ${ }^{51} \mathrm{Cr}$-labeled P815 murine mastocytoma cells at effector-to-target ratios of 10, 5, and 2.5 to 1 , as described previously. ${ }^{16}$

\section{Fas-Fas Ligand-Mediated Apoptotic Killing}

The ability of gastric T-cell clones to induce Fas-Fas ligand-mediated apoptosis was assessed using Fas ${ }^{+}$Jurkat cells as target. ${ }^{21}$ T-cell blasts from each clone were cocultured with ${ }^{51}$ Cr-labeled Jurkat cells at effector-to-target ratios of 10, 5, and 2.5 to 1 for 18 hours in the presence of PMA $(10 \mathrm{ng} / \mathrm{mL})$ and ionomycin $(1 \mathrm{mmol} / \mathrm{L})$. Specific lysis was calculated according to the formula reported above. To block Fas-Fas ligand interaction, the anti-Fas antagonistic monoclonal antibody $\mathrm{M} 3$ (Immunex Corp., Seattle, WA $)^{22}$ was used at $5 \mu \mathrm{g} / \mathrm{mL}$ final concentration in 30 minutes' pretreatment of ${ }^{51} \mathrm{Cr}$-labeled Jurkat cells. The anti-Fas or its isotype (IgG1) control was also 
added during the cytolytic assay at $2 \mu \mathrm{g} / \mathrm{mL}$ final concentration.

\section{Analysis of Fas Ligand Expression by Gastric T-Cell Lines}

T-cell blasts recovered from gastric biopsy specimens of patients with chronic gastritis and MALT lymphoma were expanded for 9-12 days in IL-2-conditioned medium to obtain a number of cells suitable for Fas ligand expression. T-cell blasts from each line were cultured for 6 hours in medium alone or in the presence of PMA $(10 \mathrm{ng} / \mathrm{mL})$ and ionomycin (1 $\mathrm{mmol} / \mathrm{L})$. After they were washed with medium/ $\mathrm{NaN}_{3}$, T-cell blasts were incubated for 30 minutes with the anti-human Fas ligand biotinylated monoclonal antibody (Clone NOK-1; Pharmingen) or the appropriate isotype (IgG1) control followed by streptavidin-phycoerythrin (Southern Biotechnology Associates, Birmingham, AL). Flow cytometry was performed on a Becton Dickinson FACScan flow cytometer, and 500010,000 events were collected per sample.

\section{Results}

\section{Antigen Specificity and Cytokine Profile of Gastric T-Cell Clones}

In vivo-activated $\mathrm{T}$ cells present in the antral infiltrates of $5 \mathrm{H}$. pylori-infected patients with low-grade MALT lymphoma and patients with $H$. pylori-induced uncomplicated chronic gastritis were isolated and cloned.

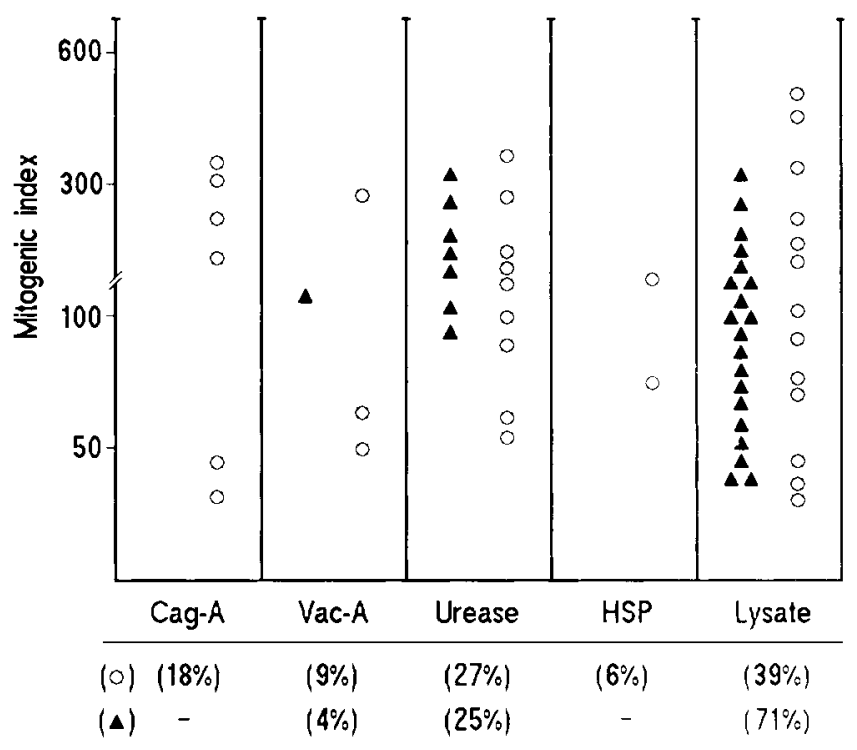

Figure 1. Antigen repertoire of $H$. pylori-reactive T-cell clones derived from the gastric mucosa of $\mathrm{H}$. pylori-infected patients with low-grade MALT B-cell lymphoma $(\boldsymbol{\Lambda})$ or uncomplicated chronic gastritis $(O)$. In vivo-activated $T$ cells were recovered from biopsy specimens of gastric mucosa and cloned by limiting dilution. T-cell blasts from each clone were seeded in triplicate cultures with irradiated autologous peripheral blood mononuclear cells in the presence of medium alone or optimal doses of crude $H$. pylori lysate $(10 \mu g / m L)$, urease, CagA, VacA, or HSP $(1 \mu \mathrm{g} / \mathrm{mL})$. After 60 hours, $\left[{ }^{3} \mathrm{H}\right]$ thymidine uptake was measured and expressed as mitogenic index.
Table 1. Cytokine Profile of H. pylori-Reactive T-Cell Clones Derived From the Antral Mucosa of Patients With MALT Lymphoma or Chronic Gastritis

\begin{tabular}{ccccc}
\hline & $\begin{array}{c}\text { No. of } \\
\text { specific }\end{array}$ & & \multicolumn{2}{c}{$\begin{array}{c}\text { No. of clones with the } \\
\text { indicated cytokine profile }\end{array}$} \\
\cline { 3 - 5 } & $\begin{array}{c}\text { clones/all } \\
\text { CD4 clones } \\
\text { obtained }\end{array}$ & Th1 & Th0 & Th2 \\
\hline Patients & Low-grade gastric & & & \\
$\begin{array}{c}\text { MALT lymphoma } \\
(n=5)\end{array}$ & $28 / 165$ & $2(7 \%)^{a, b}$ & $24(86 \%)^{c}$ & $2(7 \%)$ \\
$\begin{array}{l}\text { Uncomplicated } \\
\text { chronic gastritis } \\
(n=5)\end{array}$ & $33 / 178$ & $13(39 \%)^{b}$ & $20(61 \%)^{c}$ & $0(0 \%)$ \\
\hline
\end{tabular}

aT-cell blasts $\left(10^{6}\right)$ of each clone were cocultured for 48 hours in $1 \mathrm{~mL}$ of medium with $5 \times 10^{5}$ irradiated autologous APCs and $H$. pylori lysate $(10 \mu \mathrm{g} / \mathrm{mL})$. Supernatants were assayed for IFN- $\gamma$, IL-4, and IL-5 content. T-cell clones producing IFN- $\gamma$ but not IL- 4 or IL- 5 were coded as Th1; clones producing IL-4 or IL-5 but not IFN- $\gamma$ were coded as Th2; clones producing both IFN- $\gamma$ and IL-4 or IL- 5 were coded as Th0.

${ }^{b} \chi^{2}=8.5, P<0.005$.

${ }^{c} \chi^{2}=4.75, P<0.05$.

A total of $165 \mathrm{CD}^{+}$and $16 \mathrm{CD}^{+}$clones were obtained from the gastric biopsy specimens of MALT lymphoma; $78 \mathrm{CD}^{+}$and $21 \mathrm{CD}^{+}{ }^{+}$-cell clones were obtained from chronic gastritis. None of the $\mathrm{CD} 8^{+}$clones responded to H. pylori antigens, whereas $28 \mathrm{CD}^{+}{ }^{+}$clones from MALT lymphoma and $33 \mathrm{CD}^{+}$clones from chronic gastritis showed antigen-induced proliferation (Figure 1). In both types of patients, the proportion of $H$. pylori-specific clones ranged between $3 \%$ and $20 \%$ of the clones obtained, and each case contributed an almost equal number of clones. Among the $H$. pylori-reactive clones from MALT lymphoma, 25\% were specific for urease, $4 \%$ for VacA, and none for CagA or HSP; $71 \%$ proliferated only in response to $H$. pylori lysate. In chronic gastritis, the proportion of clones reactive to urease was similar (27\%); a number of clones were specific for CagA, VacA, or $\operatorname{HSP}(18 \%, 9 \%$, and 6\%, respectively); and $39 \%$ responded only to $H$. pylori lysate (Figure 1 ).

Upon antigen stimulation, 39\% of clones from chronic gastritis produced IFN- $\gamma$ but neither IL- 4 nor IL- 5 (Th1 profile), whereas $61 \%$ secreted both Th1- and Th2-type cytokines (Th0 profile). The 28 gastric T-cell clones from MALT lymphoma comprised a smaller proportion of Th1, more Th0, and a few Th2 clones (Table 1). At mRNA level, the 2 Th2 clones from MALT lymphoma confirmed their cytokine profile; among the other clones, irrespective of their origin, all Th1 expressed mRNA for IL-2, IFN- $\gamma$, and IL-13, whereas all Th0 clones also expressed mRNA for IL- 4 and IL- 5 with no quantitative differences in the densitometric analysis of the cytokine RNA bands (data not shown). 


\section{Antigen-Dependent B-Cell Help by H. pylori-Specific Th Clones}

To assess the ability of $H$. pylori-specific T-cell clones to provide antigen-triggered B-cell help, irradiated T-cell blasts of each clone were cocultured at 0.2-, 1-, and 5-to-1 ratios with autologous peripheral blood B cells. At a 1-to-1 T-to-B-cell ratio, all antigen-stimulated H. pylori-specific clones from either chronic gastritis or MALT lymphoma patients provided substantial help for B-cell proliferation (mean mitogenic index, 26 and 29; range, $10-45$ and 12-42, respectively; Figure 2). At a 5-to-1 T-to-B-cell ratio, all 28 Th clones from MALT lymphoma further increased B-cell proliferation, whereas a remarkable reduction (or extinction) of B-cell proliferation was observed in the presence of virtually all $33 \mathrm{Th}$ clones from chronic gastritis (Figure 2).

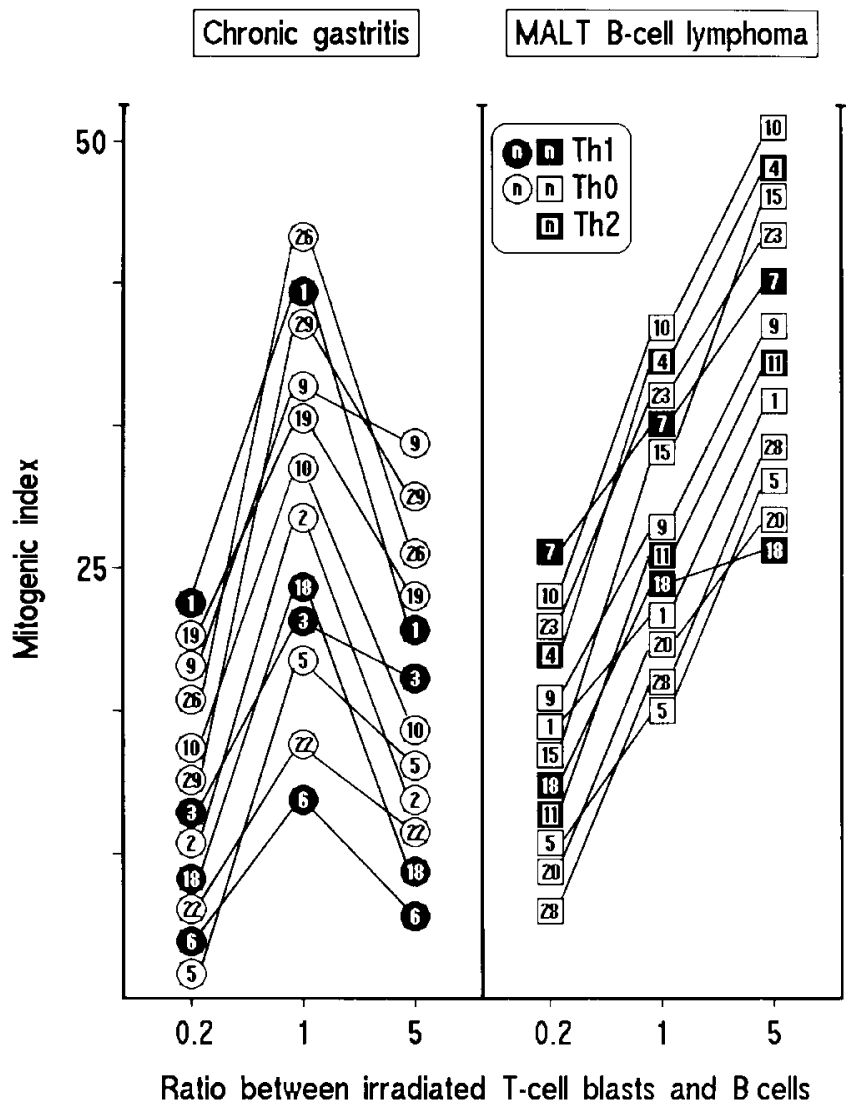

Figure 2. $H$. pylori antigen-stimulated T-cell clones derived from the gastric mucosa of patients with MALT Iymphoma provide autologous B cells with boundless help for proliferation. Irradiated T-cell blasts of each $H$. pylori-reactive clone derived from patients with gastric MALT lymphoma (squares) or chronic gastritis (circles) were cocultured for 4 days with peripheral blood autologous $B$ cells $\left(3 \times 10^{4}\right)$ at $0.2-$-, 1-, and 5-to-1 T-to-B-cell ratios in the presence of medium alone or $\mathrm{H}$. pylori antigen. Sixteen hours before harvesting, $0.5 \mu \mathrm{Ci}$ of $\left[{ }^{3} \mathrm{H}\right]$ thymidine was added, and its uptake was measured and expressed as mitogenic index. Results obtained with 2 series of 12 representative gastric clones from patients with chronic gastritis or MALT lymphoma are shown. Numbers and symbols allow the recognition of single T-cell clones in subsequent figures.

\section{Lack of Perforin-Mediated Cytotoxicity to Antigen-Presenting Autologous B Cells in Gastric T-Cell Clones From MALT Lymphoma}

Because most antigen-activated Th1 and Th0 clones express perforin-mediated cytotoxicity against antigen-presenting autologous $\mathrm{B}$ cells, ${ }^{20}$ the cytolytic potential of $H$. pylori-specific clones obtained from chronic gastritis or MALT lymphoma was assessed using antigen-pulsed ${ }^{51} \mathrm{Cr}$-labeled autologous EBV-B cells as targets. At an effector-to-target ratio of 10 to 1 , none of the $28 \mathrm{H}$. pylori-specific clones from MALT lymphoma was able to lyse target cells. In contrast, 27 of the $33 \mathrm{Th}$ clones from chronic gastritis lysed $H$. pylori antigenpresenting autologous EBV-B cells (Figure $3 A$ ). The lack of perforin-mediated cytotoxicity of the $H$. pylori-specific clones from MALT lymphoma was confirmed in a lectin-dependent cytolytic assay (Figure $3 A$ ). Among the $137 \mathrm{CD}^{+}$and $16 \mathrm{CD}^{+}$T-cell clones with undefined antigen specificity, only $13 \%$ of $\mathrm{CD}^{+}$and $44 \%$ of $\mathrm{CD}^{+}$ clones showed lectin-dependent cytotoxicity, whereas $88 \%$ of $\mathrm{CD}^{+}(P<0.0001)$ and $95 \%$ of $\mathrm{CD}^{+}(P<$ $0.0005)$ gastric clones derived from chronic gastritis were cytolytic in the same assay.

To assess whether the reduced cytolytic activity of $\mathrm{T}$ cells from patients with MALT lymphoma was peculiar to their gastric infiltrates or a general T-cell defect, PPDspecific T-cell clones derived from their peripheral blood were compared for perforin-mediated cytotoxicity with PPD-specific clones derived from the peripheral blood of patients with chronic gastritis. At an effector-to-target ratio of 10 to 1 , PPD-specific clones from MALT lymphoma and chronic gastritis were equally able to lyse PPD-pulsed autologous EBV-B cells $(70.5 \% \pm 12 \%$ and $67.3 \% \pm 17 \%$ mean \pm SD specific ${ }^{51} \mathrm{Cr}$-release, respectively).

\section{Deficiency of Fas-Fas Ligand-Mediated Apoptotic Killing in Gastric T-Cell Clones From MALT Lymphoma}

Activated $\mathrm{T}$ cells can also kill their targets by inducing apoptosis through Fas-Fas ligand interaction. ${ }^{11-13,21}$ The ability of activated gastric T-cell clones to induce ${ }^{51} \mathrm{Cr}$-release by $\mathrm{Fas}^{+}$Jurkat cells undergoing apoptosis was evaluated. Only $21 \%$ of $H$. pylori-specific clones from MALT lymphoma induced apoptosis, whereas $88 \%$ of clones from chronic gastritis induced apoptosis under the same conditions $(P<0.0001$; Figure 4$)$. The role of Fas-Fas ligand interaction in this ${ }^{51} \mathrm{Cr}$-release was confirmed by its inhibition by a blocking anti-Fas antibody (Table 2). In the series of MALT lymphoma- 


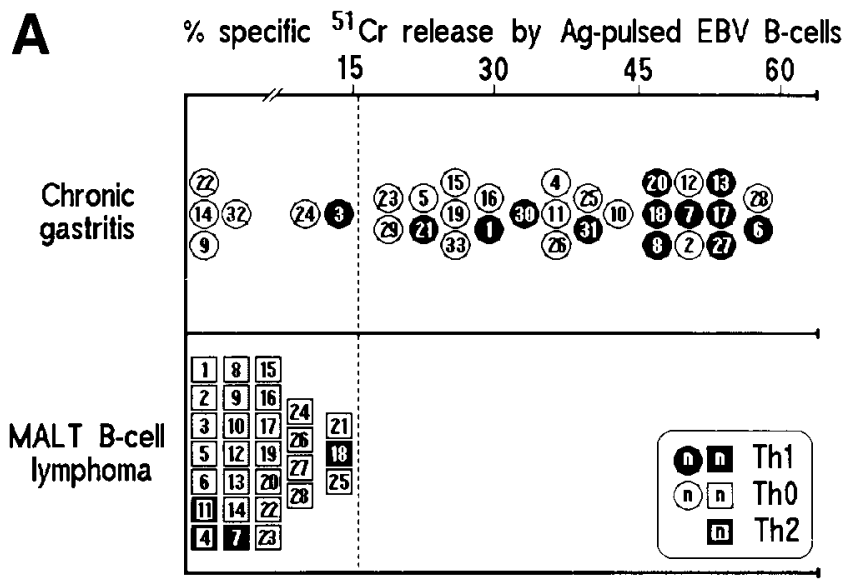

B $\%$ specific ${ }^{51} \mathrm{Cr}$ release by PHA-pulsed P815 cells

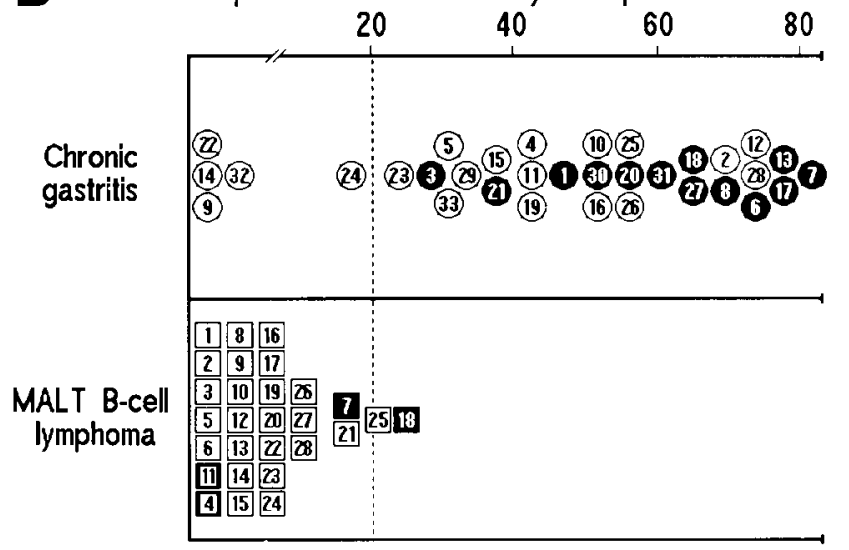

Figure 3. Failure of $H$. pylori-reactive T-cell clones derived from the gastric mucosa of patients with MALT lymphoma to express $(A)$ antigen-induced perforin-mediated cytotoxicity against antigenpresenting autologous EBV-B cells and $(B)$ lectin-dependent cytotoxicity to P815 target cells. Cytolytic activity of each $\mathrm{H}$. pylori-reactive gastric T-cell clone from patients with MALT lymphoma or chronic gastritis was tested in triplicate at an effector-to-target ratio of 10 to 1 against ${ }^{51} \mathrm{Cr}$-labeled autologous EBV-B cells pulsed with $H$. pylori antigens $(A)$ and against ${ }^{51}$ Cr-labeled P815 murine mastocytoma cell line in the presence of phytohemagglutinin (B). Percent of specific ${ }^{51} \mathrm{Cr}$ release was calculated as described in Materials and Methods. The dotted lines indicate 5 SD above the mean spontaneous release of target cells alone. Numbers and symbols allow the recognition of single T-cell clones in previous and subsequent figures.

derived clones with undefined specificity, only $27 \%$ of $\mathrm{CD}^{+}$and $63 \%$ of $\mathrm{CD}^{+}$clones induced apoptosis, whereas $91 \%$ of $\mathrm{CD}^{+}(P<0.0001)$ and $95 \%$ of $\mathrm{CD} 8^{+}$ clones $(P<0.01)$ from chronic gastritis induced apoptotic death in Jurkat cells. However, no difference was found in the proapoptotic activity of PPD-specific T-cell clones from the peripheral blood of patients with MALT lymphoma or chronic gastritis $(51.3 \% \pm 14 \%$ and $47.9 \% \pm 12 \%$ specific ${ }^{51} \mathrm{Cr}$-release, respectively).

To assess whether the poor ability of T-cell clones derived from MALT lymphoma to induce apoptosis in Jurkat cells was simply related to a deficiency of Fas ligand expression, polyclonal T-cell lines derived from gastric biopsy specimens of the same patients with MALT lymphoma and chronic gastritis were compared for Fas ligand expression before and after stimulation with PMA and ionomycin. In all of the unstimulated T-cell lines derived from MALT lymphoma and chronic gastritis biopsy specimens, the number of T-cell blasts stained by the anti-Fas ligand antibody and the mean fluorescence intensity recorded at flow cytometry did not differ from those obtained with the isotype control (Figure 5). In contrast, upon stimulation with PMA and ionomycin, all of the gastric T-cell lines derived from either MALT lymphoma or chronic gastritis showed almost equal Fas ligand expression (Figure 5).

\section{Discussion}

In vivo-activated $\mathrm{T}$ cells in the lesional gastric mucosa of 5 patients with $H$. pylori-associated low-grade MALT lymphoma were expanded in vitro and efficiently cloned to assess their specificity for $H$. pylori and functional profile. This procedure has proved useful and accurate for in vitro studies of tissue-infiltrating $\mathrm{T}$ cells in various diseases. ${ }^{23,24}$ In the progeny of gastric $\mathrm{T}$ cells from either MALT lymphoma or chronic gastritis, a noticeable proportion of T-cell clones were reactive to $H$. pylori antigens. As observed in other $H$. pylori-infected patients with uncomplicated chronic gastritis ${ }^{25}$ or peptic ulcer, ${ }^{16}$ each patient with MALT lymphoma contributed an almost equal number of gastric T-cell clones, whose functional features were consistently shared by each patient.

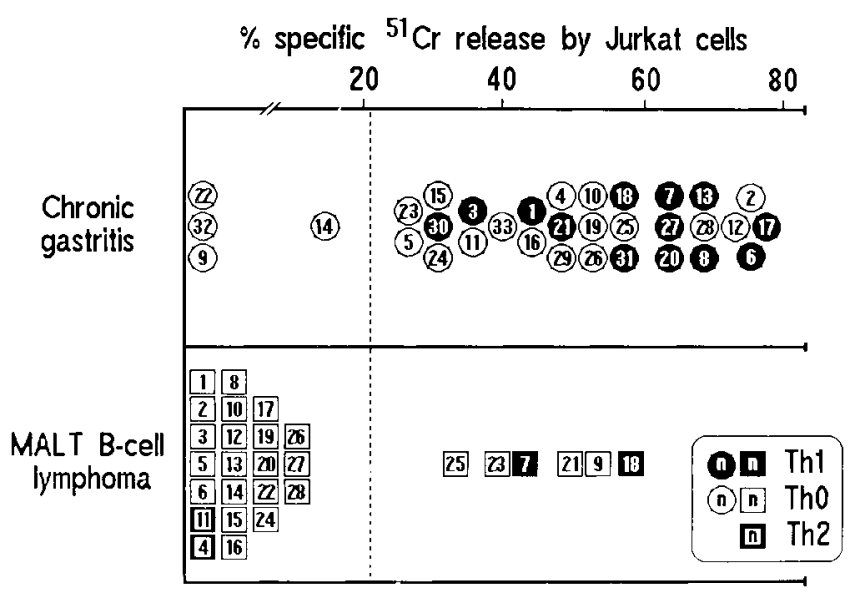

Figure 4. Reduced ability of $H$. pylori-reactive T-cell clones derived from the gastric mucosa of patients with MALT lymphoma to induce Fas-Fas ligand-mediated apoptosis and lysis in Jurkat cells. T-cell blasts of each $H$. pylori-reactive gastric T-cell clone from patients with MALT lymphoma or chronic gastritis were tested in triplicate at an effector-totarget ratio of 10 to 1 against ${ }^{51} \mathrm{Cr}$-labeled Jurkat cells in the absence or presence of $10 \mathrm{ng} / \mathrm{mL} P M A$ and $1 \mathrm{mmol} / \mathrm{L}$ ionomycin. After 18 hours, the percent of specific ${ }^{51} \mathrm{Cr}$ release was calculated as described in Materials and Methods. The dotted lines indicate 5 SD above the mean spontaneous release of target cells alone. Numbers and symbols allow the recognition of single T-cell clones in previous figures. 
Table 2. Inhibition by Anti-Fas Monoclonal Antibody of Apoptosis and Lysis Induced in Jurkat Cells by H. pylori-Reactive T-Cell Clones Derived From Gastric Mucosa of Patients With MALT Lymphoma or Chronic Gastritis

\begin{tabular}{lcc}
\hline Source of T-cell clones & Anti-Fas added & \% Specific ${ }^{51} \mathrm{Cr}_{\text {release }}{ }^{a}$ \\
\hline MALT lymphoma & & \\
Clone 18 & - & 58.3 \\
& + & 30.6 \\
Clone 21 & - & 49.2 \\
& + & 22.7 \\
Clone 25 & - & 31.8 \\
Chronic gastritis & + & 17.6 \\
Clone 6 & - & \\
& + & 74.7 \\
Clone 26 & - & 30.8 \\
& + & 56.5 \\
Clone 33 & - & 33.6 \\
& + & 40.1 \\
None & - & 21.8 \\
& + & 10.7 \\
\hline
\end{tabular}

aT-cell blasts of each clone were cocultured for 18 hours in triplicate at a 10-to-1 ratio with ${ }^{51} \mathrm{Cr}$-labeled Jurkat cells pretreated for 30 minutes with $5 \mu \mathrm{g} / \mathrm{mL}$ of the anti-Fas antagonistic M3 antibody or its isotype control in the presence of PMA $(10 \mathrm{ng} / \mathrm{mL})$ and ionomycin $(1 \mathrm{mmol} / \mathrm{L})$. Anti-Fas monoclonal antibody or its isotype control was also added during the assay at $2 \mu \mathrm{g} / \mathrm{mL}$ final concentration. The results of 6 clones representative of 24 tested are reported.

Whether infection with more aggressive $\mathrm{CagA}^{+} \mathrm{H}$. pylori strains is associated with MALT lymphoma is still controversial. ${ }^{26,27}$ Present data suggest that $\mathrm{CagA}$ is not the immunodominant target of gastric $\mathrm{T}$ cells, as in chronic gastritis complicated by peptic ulcer. ${ }^{16}$ Rather, in both MALT lymphoma and uncomplicated chronic gastritis, urease seems to be a major antigen recognized by the local T-cell response. On the other hand, most T-cell clones from MALT lymphoma responded only to $H$. pylori lysate, suggesting that some other still undefined antigens of $H$. pylori may be involved.

In comparison with clones generated from chronic gastritis, $H$. pylori-activated T-cell clones from MALT lymphoma showed higher helper activity for B-cell proliferation. This supports the concept that $H$. pylorispecific $\mathrm{T}$ cells are in some way responsible for the abnormal B-cell growth, which probably precedes and favors the development of low-grade B-cell lymphoma at gastric level in some $H$. pylori-infected patients. A possible mechanism for enhanced B-cell proliferation might be abnormal production of Th-derived cytokines active on B-cell growth. MALT lymphoma-like lesions of the gastric mucosa were found after long-term Helicobacter felis infection in aged BALB/c mice, a strain genetically prone to high production of Th2 cytokines and B-cell response. ${ }^{28}$ Th2-skewed cytokine production in the local T-cell response might account for enhanced B-cell prolif- eration in MALT lymphoma. However, apart from a lower proportion of Th1 and rare Th2 clones, most MALT lymphoma $\mathrm{T}$ cells were $\mathrm{Th} 0$, as were most clones obtained from uncomplicated chronic gastritis. Likewise, the amounts of cytokines produced at single-cell level in the 2 series of Th0 clones were comparable. Upon in vitro stimulation with $H$. pylori, strong IFN- $\gamma$ response and relatively small production of Th2 cytokines were observed in tumor-infiltrating $\mathrm{T}$ cells from 2 patients with MALT lymphoma. ${ }^{29}$ Taken together, these studies suggest that both Th1-type (IFN- $\gamma$ and IL-2) and Th2-type (IL-4, IL-10, and IL-13) cytokines, all sharing B-cell growth factor activity, ${ }^{30}$ can be secreted by $H$. pyloristimulated MALT lymphoma $\mathrm{T}$ cells, suggesting that mechanisms other than cytokines are involved in the $H$. pylori-dependent enhanced T-cell help for B-cell proliferation. Another possibility is that enhanced B-cell growth is related to defective T-cell regulation of B-cell response. Depending on antigen challenge, expansion of $\mathrm{T}$ cells occurs in the early phases of immune response. When effector mechanisms and B-cell humoral response are fully activated and pathogen clearance is possibly achieved, a decrease in antigen-induced help for B-cell proliferation is observed. In vitro, a decrease in B-cell help at high $\mathrm{T}-\mathrm{B}$-cell ratios is peculiar to Th1 and most Th0 clones, because of their concomitant expression of cytolytic killing of antigen-presenting autologous $\mathrm{B}$ cells. ${ }^{20}$ This cytolytic activity is perforin-mediated ${ }^{10,11}$ and usually lacks in Th2 clones. ${ }^{20}$ Despite similar cytokine profiles, a striking difference was found in the cytolytic potential of T-cell clones derived from MALT lymphoma or chronic gastritis. Whereas most chronic gastritis clones expressed cytotoxicity, none of the $H$. pylori-specific clones (and only a few other $\mathrm{CD}^{+}$or $\mathrm{CD}^{+}$clones) from MALT lymphoma were cytolytic.

$\mathrm{T}-\mathrm{B}$-cell interaction is a multistep process resulting in B-cell help and/or Fas-Fas ligand-mediated B-cell death depending on the functional commitment of the Th cells involved. Induction of B-cell apoptosis is a common function of Th1 and Th0 but not Th2 cells. ${ }^{31}$ In the present study, all Th1 and most Th0 clones from chronic gastritis, either reactive or nonreactive to $H$. pylori, induced Fas-Fas ligand-mediated apoptosis in target cells. In contrast, in the series of gastric clones from MALT lymphoma, only $21 \%$ of $H$. pylori-specific clones and $27 \%$ of $\mathrm{CD}^{+}$clones with undefined specificity (mainly Th1 and a few Th0) were able to induce apoptosis. The inhibitory effect of anti-Fas blocking antibody on the proapoptotic activity of these few gastric clones from MALT lymphoma allowed suspicion that the failure in the induction of apoptosis shown by the majority of MALT lymphoma-derived T-cell clones was 

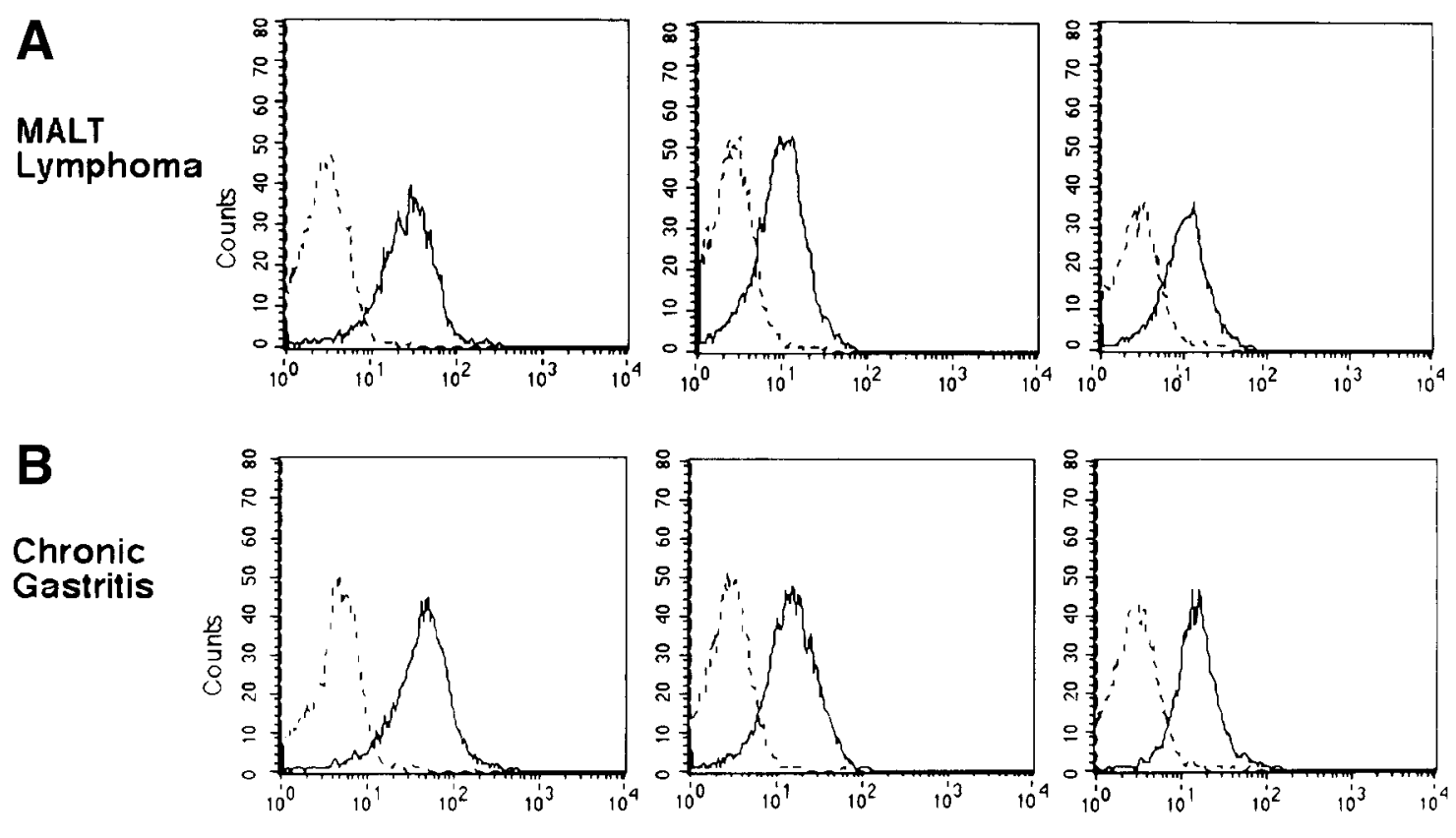

Relative fluorescence intensity

Figure 5. Membrane Fas ligand expression by activated T-cell lines derived from the gastric mucosa of patients with MALT lymphoma or chronic gastritis. T-cell blasts from each line were cultured for 6 hours in medium alone or in the presence of $10 \mathrm{ng} / \mathrm{mL} \mathrm{PMA}$ and $1 \mathrm{mmol} / \mathrm{L}$ ionomycin. After they were washed, T-cell blasts were incubated with an anti-human Fas ligand biotinylated monoclonal antibody or its isotype (IgG1) control followed by streptavidin-phycoerythrin. Flow cytometry was performed on a Becton Dickinson FACScan flow cytometer; 5000-10,000 events were collected per sample. Results obtained with 2 series of 3 representative gastric T-cell lines from patients with $(A)$ MALT lymphoma or (B) chronic gastritis are shown.

attributable simply to their inability to adequately express membrane Fas ligand. However, compared with those derived from chronic gastritis, gastric T-cell lines derived from MALT lymphoma showed no substantial difference in Fas ligand expression in terms of the proportions of positive cells or of the mean fluorescence intensity. Thus, unless most of the $T$ cells infiltrating the gastric MALT lymphoma express a Fas ligand molecule that maintains a normal immunoreactivity but is actually hampered in its function, the discrepancy between phenotypical and functional data remains unexplained.

In conclusion, gastric T cells from MALT lymphoma show both defective perforin-mediated cytotoxicity and poor ability to induce apoptosis, thus providing a possible explanation for their enhanced helper activity on B-cell proliferation. Both defects seem to be restricted to MALT lymphoma-infiltrating $\mathrm{T}$ cells, because PPDspecific $\mathrm{T}$ cells from peripheral blood of the same patients expressed the same degree of either cytolytic potential or proapoptotic activity as control clones derived from patients with chronic gastritis. The reason gastric $T$ cells of MALT lymphoma, while delivering full help to B cells, are apparently deficient in 2 mechanisms involved in the concomitant control of B-cell growth remains unclear. It has been shown that VacA toxin released by $H$. pylori strains harboring a pathogenicity island ${ }^{32}$ inhibits anti- gen processing in APCs but not the exocytosis of perforin-containing granules of natural killer cells. ${ }^{33}$ It is possible that, in some $H$. pylori-infected individuals, other bacterial components affect the development or expression of regulatory cytotoxic mechanisms on B-cell proliferation by gastric $\mathrm{T}$ cells, allowing exhaustive and unbalanced B-cell help and lymphomagenesis.

\section{References}

1. Isaacson PG, Wright DH. Malignant lymphoma of mucosaassociated lymphoid tissue. A distinctive type of B-cell lymphoma. Cancer 1983;52:1410-1416.

2. Parsonnet J, Hansen S, Rodriguez L, Gelb AB, Warnek RA, Jellum E, Orentreich N, Vogelman JH, Friedman GD. Helicobacter pylori infection and gastric lymphoma. N Engl J Med 1994;330:12671271.

3. Isaacson PG. Gastrointestinal lymphoma. Hum Pathol 1994;25: 1020-1029.

4. Greiner A, Knorr C, Qin Y, Sebald W, Schimpl A, Banchereau J, Muller-Hermelink HK. Low-grade B cell lymphomas of mucosaassociated lymphoid tissue (MALT-type) require CD40-mediated signaling and Th2-type cytokines for in vitro growth and differentiation. Am J Pathol 1997; 150:1583-1593.

5. Hussell T, Isaacson PG, Crabtree JE, Spencer J. The response of cells from low-grade B-cell gastric lymphomas of mucosaassociated lymphoid tissue to Helicobacter pylori. Lancet 1993; 342:571-574.

6. Hussell T, Isaacson PG, Crabtree JE, Spencer J. Helicobacter pylori-specific tumor-infiltrating $\mathrm{T}$ cells provide contact dependent help for the growth of malignant $B$ cells in low-grade gastric 
lymphoma of mucosa-associated lymphoid tissue. J Pathol 1996; 178:122-127.

7. Wotherspoon AC, Doglioni C, Diss TC, Pan L, Moschini A, De Boni $M$, Isaacson PG. Regression of primary low-grade B-cell gastric lymphoma of mucosa-associated lymphoid tissue after eradication of Helicobacter pylori. Lancet 1993;342:575-577.

8. Bayerdoffer E, Neubauer A, Rudolph B, Thiede C, Lehn N, Eidt S, Stolte M. Regression of primary gastric lymphoma of mucosaassociated lymphoid tissue after cure of Helicobacter pylori infection. Lancet 1995;345:1591-1594.

9. Wright SC, Zhong J, Larrick JW. Inhibition of apoptosis as a mechanism of tumor promotion. FASEB J 1994;8:654-660.

10. Lowin B, Hahne M, Mattman C, Tschopp J. Cytolytic T-cell cytotoxicity is mediated through perforin and Fas lytic pathways. Nature 1994;370:650-652.

11. Kagi D, Vignaux F, Burki K, Depraetere V, Nagata S, Hengartener $\mathrm{H}$, Golstein P. Fas and perforin pathways as major mechanism of T-cell mediated cytoxicity. Science 1994;265:528-530.

12. Williams GT. Programmed cell death: apoptosis and oncogenesis. Cell 1991;65:1097-1098.

13. Wang J, Taniuchi I, Maekawa Y, Howard M, Cooper MD, Watanabe T. Expression and function of Fas antigen on activated murine B cells. Eur J Immunol 1996;26:92-96.

14. Watanabe-Fukunaga R, Brannan $\mathrm{Cl}$, Copeland NG, Jenkins NA, Nagata S. Lymphoproliferation disorder in mice explained by defects in Fas antigen that mediates apoptosis. Nature 1992;356: 314-317.

15. Takahashi T, Tanaka M, Brannan Cl, Jenkins NA, Copeland NG, Suda T, Nagata S. Generalized lymphoproliferative disease in mice caused by a point mutation in the Fas ligand. Cell 1994;76: 969-976.

16. D'Elios MM, Manghetti M, De Carli M, Costa F, Baldari CT, Burroni D, Telford JL, Romagnani S, Del Prete G. Th1 effector cells specific for Helicobacter pylori in the gastric antrum of patients with peptic ulcer disease. J Immunol 1997;158:962-967.

17. Del Prete G, De Carli M, Mastromauro C, Biagiotti R, Macchia D, Falagiani P, Ricci M, Romagnani S. Purified protein derivative of Mycobacterium tuberculosis and excretory-secretory antigen(s) of Toxocara canis expand in vitro human T cells with stable and opposite (type $1 \mathrm{~T}$ helper or type $2 \mathrm{~T}$ helper) profile of cytokine production. J Clin Invest 1991;88:346-350.

18. Marchetti M, Aricò B, Burroni D, Figura N, Rappuoli R, Ghiara P. Development of a mouse model of Helicobacter pylori infection that mimics human disease. Science 1995;267:1655-1658.

19. Naylor MS, Relf M, Balkwill FR. Northern analysis, ribonuclease protection and in situ analysis of cytokine messenger RNA. In: Balkwill FR, ed. Cytokines. A practical approach. Oxford, England: University Press, 1995; 35-56.

20. Del Prete G, De Carli M, Ricci M, Romagnani S. Helper activity for immunoglobulin synthesis of Thelper type 1 (Th1) and Th2 human T cell clones: the help of Th1 clones is limited by their cytolytic capacity. J Exp Med 1991;174:809-813.

21. Vergelli M, Hemmer B, Muraro PA, Tranquill L, Biddison WE, Sarin A, McFarland HF, Martin R. Human autoreactive $\mathrm{CD}^{+}{ }^{+} \mathrm{T}$ cell clones use perforin- or Fas/Fas ligand-mediated pathways for target cell lysis. J Immunol 1997;158:2756-2761.

22. Ramsdell F, Seaman MS, Miller RE, Picha KS, Kennedy MK, Lynch
DH. Differential ability of Th1 and Th2 cells to express Fas ligand and to undergo activation-induced cell death. Int Immunol 1994; 6:1545-1553.

23. Linsley PS. Immunological techniques technology: a tale of two themes. Curr Opin Immunol 1997;9:175-176.

24. Carter LL, Swain SL. Single cell analyses of cytokine production. Curr Opin Immunol 1997;9:177-182.

25. D'Elios MM, Manghetti M, Almerigogna F, Amedei A, Costa F, Burroni D, Baldari CT, Romagnani S, Telford JL, Del Prete G. Different cytokine profile and antigen-specificity repertoire in Helicobacter pylori-specific $T$ cell clones from the antrum of chronic gastritis patients with or without peptic ulcer. Eur J Immunol 1997;27: 1751-1755.

26. De Jong D, Van Der Hulst RWM, Pals G, Van Dijk W, Van der Ende A, Tytgat GNJ, Taam BG, Boot H. Gastric non-Hodgkin lymphomas of mucosa-associated lymphoid tissue are not associated with more aggressive Helicobacter pylori strains as identified by CagA. Am J Clin Pathol 1996;106:670-675.

27. Eck M, Schmauber B, Haas R, Greiner A, Czub S, MullerHermelink HK. MALT-type lymphoma of the stomach is associated with Helicobacter pylori strains expressing the CagA protein. Gastroenterology 1997;112:1482-1486.

28. Enno A, O'Rourke JL, Howlett CR, Jack A, Dixon MF, Lee A. MALToma-like lesions in the murine gastric mucosa after longterm infection with Helicobacter felis. A mouse model of Helicobacter pylori-induced gastric lymphoma. Am J Pathol 1995; 47:217222.

29. Hauer AC, Finn TM, MacDonald TT, Spencer J, Isaacson PG. Analysis of Th1 and Th2 cytokine production in low grade B cell gastric MALT-type lymphomas stimulated in vitro with Helicobacter pylori. J Clin Pathol 1997;150:957-959.

30. Jelinek DF, Lipsky PE. Regulation of human B lymphocyte activation, proliferation and differentiation. Adv Immunol 1987;40: $1-59$.

31. He X, Zhong W, Goronzy JJ, Weyand CM. Induction of B cell apoptosis by Th0, but not Th2, CD4 ${ }^{+} \mathrm{T}$ cells. J Clin Invest 1995;95:564-570.

32. Telford JL, Ghiara P, Dell'Orco M, Comanducci M, Burroni D, Bugnoli M, Tecce MF, Censini S, Covacci A, Xiang Z, Rappuoli R. Gene structure of the Helicobacter pylori cytotoxin and evidence of its key role in gastric disease. J Exp Med 1994;179:16531658.

33. Molinari M, Salio M, Galli C, Norais N, Rappuoli R, Lanzavecchia A, Montecucco C. Selective inhibition of li-dependent antigen presentation by Helicobacter pylori toxin VacA. J Exp Med 1998; 187:135-140.

Received April 1, 1999. Accepted July 13, 1999.

Address requests for reprints to: Gianfranco Del Prete, M.D., Department of Internal Medicine and Immunoallergology, Viale Morgagni 85-50134 Florence, Italy. e-mail: g.delprete@mednuc2. dfc.unifi.it; fax: (39) 055-4378103.

Supported in part by grants from the Associazione Italiana per la Ricerca sul Cancro and the University of Florence. Dr D'Elios received the 1997 Byk Gulden Italia Award for Research in Gastroenterology. 